\title{
Inclusivity and Diversity in ELT Material: Critical Textual Analysis as a Pedagogical Tool
}

\section{Sreemali Herath*}

Postgraduate Institute for English, The Open University of Sri Lanka, Sri Lanka

\section{Abstract}

Promoting equity and diversity within the classroom and the wider school culture is often overlooked in most educational contexts. The focus on student diversity is important as teachers need to be able to use classroom instruction and communication to make their classes inclusive for all learners. Yet, how can classrooms be inclusive and safe learning environments that offer all students the space to grow and reach their full potential? How can teachers design and deliver lessons so that all learners feel they belong to the school community? How can teachers help their learners appropriate pedagogical content on their own terms? These are concerns this paper attempts to answer. Focusing on English Language Teaching (ELT) material, it discusses how educational discoureses in textbooks reproduce inequalities that exist outside of the classroom and how critical discourse analysis (CDA) can be used to deconstructs texts in order to explore ways in which they relate to broader sociopolitical contexts. Drawing on selected tenets of CDA, this study discusses how they can be used as an analytical tool to critically examine the relations between

*Corresponding should be addressed to Dr. Sreemali Herath, Postgraduate Institute for English, The Open University of Sri Lanka, Sri Lanka.

Email: smher@ou.ac.lk

https://orcid.org/0000-0002-7403-7346

(Received 28 $8^{\text {th }}$ February 2020; Revised $8^{\text {th }}$ May 2020; Accepted $15^{\text {th }}$ May 2020) (C) OUSL)

(1) (O) This article is published under the Creative Commons Attribution-Share Alike 4.0 International License (CC- 
discourse, power, dominance, and social inequality present in textbooks and identify ways in which educators can adapt and appropriate material in ways that help their learners to build on the cultural and linguistic capital they bring with them to the classroom.

Key words: ELT textbooks, diversity, inclusivity, critical discourse analysis

\section{Introduction}

In any classroom, in any social context, in any part of the world, no two learners are alike. They are culturally, linguistically, and socially different. Their experiences are different and so are their expectations. In addition to personal differences, today's learners live in a world where they are exposed to intensely expanding social and visual media. For them, literacy consists of a diverse range of multimodal literacies, most of which are not included in the school curricula. How are inequalities that exist in the larger society reproduced in textbooks? How do existing school curricula, and more specifically the textbooks, sufficiently address the needs of this diverse community? How can classrooms be made more inclusive? How can teachers be assisted to critically analyze the curricula in ways to help them design lessons that are inclusive and effective? How can teachers make their classrooms inclusive so they can cater to the needs of a diverse student population? This is an even greater challenge for English language teachers as they need to not only introduce their learners to the language and the content but also to help them appropriate the language in their own terms. This paper is a discussion about how social inequities are reproduced in textbooks and how critical discourse analysis can support educators to read texts and adopt them in ways that help their learners appreciate what they learn.

\section{Social reproduction of texts}

Cummins' (2001a, 2001b) "Framework for academic language learning" is based on the premise that in "contexts of cultural, linguistic and economic diversity where social inequality inevitably 
exists, ... interactions are never neutral: they either challenge the operation of coercive relations of power in the wider society or they reinforce these power relations" (2001a, p. 125). Cummins further asserts that teacher-student interaction must affirm students' cultural, linguistic and personal identities in order to augment the learning process (p. 126). He emphasizes the importance of providing students the opportunity to focus on meaning, language and use in both spoken and written contexts. Activation of learners' prior experiences and background knowledge allows the learners to value their cultures on the one hand, and promote maximum "cognitive engagement" on the other (p. 131). This framework is important in understanding to what extent materials presented in the text and the activities that accompany them take into consideration the actual socio-political realities the students encounter everyday. Cummins' model emphasizes how important it is for teachers and school authorities to be sensitive to the needs of the ever increasing diversity of the student population. He is not alone in suggesting that it is time that schools change to address the needs of the students. Delpit (1988) argues that,

Children have the right to their own language, their own culture. We must fight the system by insisting that children be allowed to express themselves in their own language styles. It's not they, the children, who must change, but the schools. To push children to do anything else is repressive and reactionary (p. 291).

These views throw light on teacher education, curriculum design and material development. They also call for the need to employ critical approaches to language teaching and learning that attempt to link language learning to social change.

As Bourdieu (2000) discusses, the production and the reproduction of legitimate language is one of the functions of education. What counts as legitimate language is a product of social evaluation. Education evaluates forms of language (dialects, accents) and what is posited as the legitimate language is determined by the linguistic market, which is a reflection of dominant social relations in society in general. He argues that all linguistic practices are measured against what is considered to be 
"legitimate practices" or practices of those who are dominant. $\mathrm{He}$ argues:

The dominant competence functions as a linguistic capital, securing a profit of distinction in its relation to other competencies only in so far as certain conditions (the unification of the market and the unequal distribution of the chances of access to the means of production of legitimate competence, and to legitimate places of expression) are continuously fulfilled, so that the groups that possess that competence are able to impose it as the only legitimate one in the formal markets (the fashionable, educational, political and administrative markets) and in most of the linguistic interactions that are involved in. (p. 475)

For example, textbooks are an integral part of education, therefore, the language and the information reproduced in them are those of the dominant social groups. Especially in educational contexts where the students use the textbooks to prepare for standardized high stake examination, what counts as legitimate language is the language that is present in the textbooks. Although this language and the content in textbooks might be familiar to students from dominant and elite social groups, it might be very distant to minority learners and learners from disadvantaged backgrounds.

In his discussion about forms of capital, Bourdieu (1986) argues that each individual possesses different types of capital, and that this capital has different values in different contexts. He defines cultural capital as:

... a theoretical hypothesis which made it possible to explain the unequal scholastic achievement of children originating from different social classes by relating academic success, i.e., the specific profits which children from the different classes and class fractions can obtain in the academic market, the distribution of cultural capital between the classes and class fractions (p. 243).

One of the forms of cultural capital is "embodied cultural capital" or the habitus one internalizes through socialization and education. This includes attitudes, habits, dispositions, etc. 
However, none of these forms of capital will be valued unless they are acknowledged as having legitimacy. For instance, learners from English speaking backgrounds or those with more exposure to the language and more importantly those who speak a standard variety of English would have the linguistic capital to succeed in school. This linguistic capital can later be turned into economic capital in the form of access to better educational and employment opportunities.

\section{Discourse and discrimination}

Discourse is often a tool dominant groups and institutions use to discriminate against minority groups. Though it is quite different from physical violence, it is equally painful. Elite discourse may seem harmless, but it has harmful consequences. It is therefore a form of linguistic discrimination. However, it is important to note that this form of discrimination very often takes place at a very symbolic level (Smitherman-Donaldson \& van Dijk, 1988). The discourse in textbooks is very much part of the dominant discourse. As van Dijk (1993a) asserts "educational discourse and organizations ... contribute to the reproduction of an ideology that supports the ethnic status quo" (p. 238). School is the context for the "acquisition and confirmation of ethnic and racial beliefs" ( $p$. 198). Textbooks show the perspectives and the interests of the dominant groups. In the absence of alternative modes of influence, textbook discourse plays a crucial role in shaping the world view of young learners. Very often textbooks portray superficial information about minority cultures that obscure the hegemony of the dominant group. Such stereotypical representations affect both the majority and the minority learners. By the time students are in secondary school, they already have some knowledge of other ethnic groups through, for instance, personal experiences, peers, parents, and the media. Biased representations of diverse communities in textbooks can confirm these stereotypes or prejudices. Moreover, the more subtle and indirect forms of marginalization and inferiorization of minorities in educational discourse establishes more sophisticated beliefs. Though there might not be instances of overt discrimination, the absence of sufficient representation of diverse communities is still 
discrimination. As van Dijk (1993a) states, it's a form of "symbolic discrimination" (p. 18).

That is why the content as well as the activities in the textbooks should explicitly take into consideration the possible presence of minority learners in the classroom. Textbooks should feature a broad perspective that gives credit to all major ethnic groups in the country and the world. Educational discourses need to aim to develop knowledge and attitudes needed to participate in the overcoming and resisting of various forms of discrimination. Moreover, questioning the characterization, the language, the historical correctness, the cultural authenticity and the illustrations can help in detecting bias in textbooks (van Dijk, 1993a).

\section{Critical Discourse Analysis (CDA)}

The approach to critical textual analysis this paper draws on derives from the analytical frameworks of Fairclough (1993) and Pennycook (2001). For Fairclough (1993), the aims of CDA are three-fold: first, to "systematically explore the often opaque relationships of causality and determination" between texts and wider social and cultural structures and relations; second, to investigate how texts are shaped by relations of power and struggles over power. Finally, it explores how power is maintained through the opacity of these relationships between discourse and society (p. 135). Pennycook's (2001) approach to textual analysis attempts to move away from mainstream critical work. Firstly, it is based on the premise that literacy is always political. Secondly, it views texts and literacy practices as located in social contexts. What is meant by context is not just the immediate surroundings, but more importantly the "historical' and "discursive" context of texts and the readers. In a society that continues to be overshadowed by its past, a deconstruction of texts would be incomplete if it fails to take into consideration the past. Thirdly, "texts do not mean until they are interpreted" (p. 111), therefore it takes into account text "production" as well as "reception" (p.111). However, Pennycook is careful to point out the necessity of avoiding "an overdetermination by social structure" and "an 
underdetermination that suggests that texts are simply open to all interpretations" (p. 111). He draws on Hall's (1994) notion of "preferred meanings" to point out that texts may be interpreted, negotiated, or contested in keeping with these preferred or dominant meanings. Though this might not necessarily provide an answer to the meaning of the text, it would allow the reader to map out different meanings that can be located in the text (Pennycook, 2001).

Some cornerstones of CDA that lends itself to textual analysis are discussed below.

\section{Discourse in CDA}

A discussion of CDA should begin with a definition of discourse proper. It is a term that is used differently in different disciplines and by different researchers. In the English speaking world discourse is used to refer to both spoken and written texts (Weiss \& Wodak, 2003). Fairclough (1993) extends this definition to include "semiotic practice in other semiotic modalities such as photography and non-verbal (e.g. gestural) communication" (p. 134). McLaren (1989) refers to discursive practices as the "rules by which discourses are formed, rules that govern what can be said and what must remain unsaid, who can speak with authority and who must listen" (p. 180). Educational institutions such as schools are governed by discursive practices.

For Fairclough (1992), discourse is a political and ideological practice. As a political practice discourse "establishes, sustains and changes power relations, and the collective entities ... between which power relations obtain" (p. 67). And, as an ideological practice discourse "constitutes, naturalizes, sustains and changes significations of the world from diverse positions in power relations" (p. 67). Such a twofold view of discourse is important in understanding how educational discourse in English textbooks presents and naturalizes certain experiences as common realties. This view also helps in understanding what realities and experiences the texts promote. 
Discourse, therefore, is socially constitutive and constituted. It creates situations, knowledge, and social identities and relationships between people. It is discourse that helps to reproduce and sustain the status quo, which inevitably associates discourse with power. The ideological effects of powerful discursive practices can produce unequal power relations in society. However, for CDA, discourse by itself is not powerful; but, it gains power by the use of powerful people (Weiss \& Wodak, 2003). As Hall (1994) asserts, it is the dominant discourses or the discourses that have the "stamp of truth" that constitute knowledge. Information presented in textbooks are examples of dominant discourses that carry the "stamp of truth" for students preparing for standardized exams and as such they have a tendancy to accept and internalize the textbook content as the truth. Moreover, the educational and the social backgrounds of the authors would shape what is included and excluded from the text. However, this does not mean that learners and teachers alike are only influenced by textbook discourse; they also have the power to influence or resist the discourse in return.

\section{"Technologization" of Discourse}

"Technologization" of language is a striking feature of contemporary society (Fairclough, 1992). It is experienced in the form of "top-down imposition of new discursive practices by organizations upon their members" (Fairclough, 1993, p. 141). These top-down forms of imposition could include the media, the demands of the corporate sector etc. As Fairclough (1992) discusses, one example of the technologization of discourse is the emphasis on spoken language skills within language education. This demand is a result of the changing nature of the demands of the world of work. Technologization affects not only language, but also non-verbal communication as well as images. Fairclough (1992) discusses the importance of developing critical awareness in language teaching in such a context. He argues,

If power relations are indeed increasingly coming to be exercised implicitly in language, and if language practices are indeed coming to be consciously controlled and inculcated, then a linguistics which contents itself with 
describing language practices without trying to explain them, and relate them to the social and power relations which underlie them, seem to be missing an important point (p. 6).

He asserts that a critical consciousness is crucial in being an effective citizen in a democratic society.

\section{Ideology}

Ideology is another cornerstone of CDA that needs to be defined. Thompson (1990) points out that the term ideology originated in eighteenth century France, and since then has been given different functions and meanings over time. "Ideology, for CDA, is seen as an important means of establishing and maintaining unequal relations of power" (Weiss \& Wodak, 2003). Cortazzi and Jin (1999) view textbooks as ideology. For them, textbooks "reflect a worldview or cultural system, a social construction that may be imposed on teachers and students and that indirectly constructs their view of a culture" (p. 200). They argue that this aspect in textbooks very often goes unrecognized. The interest-based perspective can be revealed through questions as "In whose interest is this text written and why?" (p. 200). The country in which the textbook was published, commercial interests, and the views or interests of decision makers who choose a book can play an important role in the cultural content of the textbooks. Or, as discussed in de Castell, Luke and Luke (1989) and Apple and Christian-Smith (1991) textbooks can function as a form of cultural politics by inclusion or exclusion of certain socio-political, cultural, or economic realities.

\section{Power and cognition}

At the heart of any critical approach to language teaching and learning are notions of power and how power is reproduced through texts. According to van Dijk (1993b), there is a cognitive dimension to power, where discourse, beliefs, ideologies, and attitudes are "managed" to reflect particular dominant discourses and ideologies. van Dijk terms these modes of access to the social reality "social cognitions"; and, the social cognitions that "reflect 
the basic aims, interests and values of groups" are ideologies (p. 258). The values and interests the educational discourse promote are often shaped by the writers' own sociopolitical affiliations. The authors of the textbooks have the power to shape the textbook content to a degree and in conformity to dominant educational standards and agendas. This is based on Foucault's (1989) notion that power operates throughout society in both micro and macro settings and that it should not be viewed only as necessarily adverse or restrictive, but as something that also creates opportunities for resistance or transformation (Pennycook, 2001).

The resistance and the questioning of the educational discourse presented in textbooks would not take place if power ceased to exist. Therefore, power should be viewed as productive rather than solely restrictive or repressive. Foucault's notions of power are pertinent to the ideological deconstruction of textbooks. It does not view readers as passive recipients who are being controlled and determined by presentations in the text or are participants in what Freire (2000) called "banking education" but rather as active coconstructors of meaning.

\section{Intertextuality}

Pennycook (2001) discusses the importance of intertextuality or the manner in which discourses are constructed through intertextual relations. According to Bazerman (2004) all texts are created from a "sea" of former texts. We have seen or heard most of the words and phrases that we use; and, we understand texts that are within that textual "sea". Intertextuality describes how certain genres of discourse might borrow style and content from other genres (Cameron, 2001). All textbooks, and ELT textbooks more so, draw on excerpts from fictional and non-fictional books and other forms of literature, newspaper articles, advertisements, various documents used in the corporate sector etc.

\section{"Inclusivity" and "Inappropriacy"}

Gray (2002) in his study about global textbooks identifies similarities in the content of ELT textbooks published for the global market. This is due to the fact that publishers provide textbook 
writers guidelines as to what needs to be included and excluded in text. This includes inclusivity which refers to the non-sexist way men and women are portrayed in the text and "inappropriacy" which refers to the avoidance of certain topics that might offend the buyer. One of the main reasons these books follow these guidelines is to ensure that there is a wider global market.

Under the headings "Images of women" and "Women in language" the "inclusivity" guidelines clearly states how women should be represented and how sexist language should be avoided. This includes artwork, names in exercises, voices in tapes, videos, avoiding stereotyping etc. Going hand in hand with "inclusivity" is "inappropriacy", or topics that should be avoided. "Some publishers provide lists of proscribed topics, while others rely informally on the acronym PARSNIP (politics, alcohol, religion, sex, narcotics, isms and pork) as a rule of the thumb" (Gray, 2002, p. 159). Gray notes that ELT textbook are beginning to look more alike and are stripped of any distinctive cultural characteristics.

\section{Visual literacy in ELT textbooks}

A critical textual analysis is incomplete if it does not take into account visual literacies. Fairclough's (1993) definition of discourse is extended to semiotic practices such as photographs. A critical discourse analysis of ELT textbooks need to focus on the written discourse as well as the visual representations such as photographs, cartoons, clip-arts and other forms of drawings. As Klein (1985) asserts, "Not only do words reflect bias-so too do the pictures in books. And they do it at the flick of a page, confirming an image in the mind or flashing a new one" (p. 7). While images could be very effective in the teaching of any language, they could have a greater impact on the learners than the written discourse. Corbett (2003) discusses how visuals can be exploited for their cultural significance as well as their language learning potential. Exploration of images produced by different cultures can be exploited to enhance understanding of other social and ethnic groups. 
According to Kress and van Leeuwen (1996), visual images are a way of sending messages. While there are inherent differences between the visual images and verbal messages, images could be analyzed along linguistic lines:

What in language is realized by locative prepositions, is realized in pictures by the formal characteristics that create the contrast between the foreground and background. This is not to say that all the relations that can be realized in language can also be realized in pictures, or vice versa, that all the relations that can be realized in the pictures can also be realized in language. Rather, a given culture has a range of general, possible relations which is not tied to expression in any particular semiotic code, although some relations can only be realized in the pictures, and other only in words, or some more easily in pictures and other more easily in words. (p. 142)

Corbett (2003) argues that visual images have a "vocabulary" and a "grammar". The vocabulary consists of the content of the picture. These pictures, like vocabulary will have denotational and connotational meanings. These meanings are culturally situated and can be compared and contrasted across different contexts. The "grammar" of the image is the relationship between those people or objects represented by the image. Corbett (2003) categorizes images as narrative (transitive) images in which the characters act upon each other in some way, and descriptive (intransitive) images, in which a character or a set of characters are simply described.

Corbett (2003) also discusses the visual significance of the English language. On the one hand, in former colonies, English is still perceived as the language of the colonizer and it is the language of the elite. On the other hand, English is the language of global economic, political and technological power (Crystal, 1997). Against such a backdrop, an analysis of visuals would assist in understanding the extent to which the textbooks attempt to bridge or separate local learners. 


\section{Standard language ideology}

A deconstruction of textbooks is incomplete if it does not touch on standard language and language standards. However arbitrary the notion of 'standards' is, standards do exist, and it is standards that function as gatekeepers to employment, higher education, social mobility or even ones personal life. Jenkins (2003) defines a standard language as,

... a term used for the variety of language which is considered to be the norm. It is the variety held up as the optimum for educational purposes and used as a yardstick against which other varieties of the language are measured. Being a prestige variety, a standard variety is spoken by a minority of people within a society, typically those occupying positions of power. (p. 29) (emphasis in the original)

Language standards "are prescriptive language rules which together constitute the standard and which to all members of the community are exposed and urged to conform during education, regardless of the local variety" (Jenkins, 2003, p. 29). Parakrama (1995) while critiquing the arbitrary nature of language standards argues that language standards do not favor those who speak new varieties of English.

What is considered to be the standard variety of English in Sri Lanka clearly falls into the description given by Jenkins. According to Gunesekera (2005) "the English used by the Sri Lankan elite is Standard Sri Lankan English (SLE), which is part and parcel of belonging to the 'English speaking' class" (p. 24). Therefore, what is considered to be the standard variety of SLE is a variety used by an exclusive minority. All these findings reveal the importance of speaking a standard variety of English, however arbitrary it might be.

Advocates of critical pedagogies such as Pennycook (2001) and Canagarajah (1993) critique the notion of prescribing standard language in ELT. They argue that the learners should be allowed to bring in their own varieties of English to the class. However 
liberal these ideas may be, success in language learning is very much shaped by how well one communicates in the standard variety. Especially in contexts where learners face highly competitive standardized examinations, it is important to teach them the standard variety of English. Very often the only time a learner might have access to a standard variety of English would be in school. If the varieties used by learners are considered to be sub-standard varieties, which, when spoken in society will marginalize them, it is crucial that textbooks and classroom instruction promote standard varieties.

Parakrama (1995), who accepts the importance of standards, advocates the importance of broadening them. Broadening the standards is a means through which English could be made a more inclusive language. However, the attitudes towards English of those who speak English and those who do not are so deeply rooted that the acceptance of broader standards is going to be a slow and lengthy process. Corson (1999) asserts that "a myriad of language varieties exist everywhere ... without people having much awareness of them at all" (p. 148). He believes that educators need to promote critical awareness of varieties. In his discussion about CLA in school and curriculum, he states that the teachers need to create the space for discussion about what counts as prestigious language for them and what varieties don't. It starts by 'asking children if they knew the reasons for their biases" (p. 150) about language. "Whole-class discussions" could help students to reject reasons for prejudice and instead "focus on reasons to do with social power and with historical events" (p. 150). Marginalized discourse varieties should not remain marginalized or discarded along with foreign varieties. Learners should be encouraged to draw on these varieties for meaning making and understanding the larger structures of power. Taking a similar line of arguments as Delpit (1995), Cope and Kalantzis (1993) argue that disadvantaged learners need explicit instruction in the standard forms of language. 


\section{Cultural reflections in ELT materials}

A textual analysis also needs to be concerned with how cultures are defined and reproduced for readers. The term culture has different meanings. Cortazzi and Jin (1999) view culture as "a framework of assumptions, ideas, and beliefs that are used to interpret other people's actions, words and patterns of thinking" (p. 196). Although the manner in which one views another culture is very subjective, it is important to make language learners aware of the different cultural frameworks. As Cortazzi \& Jin (1999) point out,

...it is crucial that foreign language learners should become aware of differing cultural frameworks, both their own and those of others; otherwise they will use their own cultural system to interpret the target-language messages whose intended meaning may well be predicted on quite different cultural assumptions (p. 197).

What is important to note in the theory on EFL material development and intercultural competence is the manner in which culture is compartmentalized as 'source culture' or the learners' own culture and 'target culture' or the culture in which the target language is used as the first language (Alptekin, 1993; Cortazzi \& Jin, 1999; Sheldon, 1998). This dichotomy does not necessarily apply to the Sri Lankan situation. However, what is said about developing intercultural competence can be applied to developing awareness and cultural competence about the various local cultures.

Intercultural competence, according to Meyer (1991) is the ability of a person to be flexible when confronted with actions, attitudes and expectations that are representative of another culture but also to see one's own culture in a new or 'strange' way (Cortazzi \& Jin, 1999). Therefore, ELT materials should reflect a range of cultural contexts that include intercultural elements and should raise the learners' intercultural awareness. Otherwise the learners will be lead to believe in a unified, monolithic culture. There should be variation in terms of intra-cultural and inter-cultural elements. Intercultural competence takes place in situations which demand 
the learners to negotiate the meaning and identity with the author of the textbook and the cultural content. Cortazzi and Jin view learning culture as a dialogue between the teacher, the students and the textbook. Neither the students nor the teachers are blank slates; they will bring some cultural knowledge to the discussion. Moreover, the manner in which the teacher interprets and teaches culture would be shaped by his/her own education. They discuss the importance of using a textbook evaluation checklist that focuses on the cultural content of textbooks (Cortazzi \& Jin, 1999).

\section{Conclusion}

Textbookes used in schools are conceived and designed by people with interests and they are often a reproduction of social realities that are close to the lives of priviledged communities. Yet, in educational contexts in which student success is measured through standardized examinations, textbooks and their contents become realities that learners internalize and reproduce at exams. This paper is a critical discussion of how larger social realities are reproduced in educational resources and how CDA can be an analytical tool that helps teachers to scrutinize textbooks and rethink instruction in ways that help all learners to fully engage in the teaching-learning process irrespective of their sociocultural backgrounds.

\section{Reference}

Alptekin, C. (1993). Target language culture in EFL materials. ELT Journal, 47(2), 136-143. DOI: 10.1093/elt/47.2.136

Apple, M. W. \& Christian-Smith, L. K. (Eds.) (1991). The politics of the textbook. New York: Routledge. DPI: $10.4324 / 9781315021089$

Bazerman, B. (2004). Intertextuality: How texts rely on other texts. In C. Bazerman \& P. Prior (Eds.), What writing does and how it does it: An introduction to analyzing texts and textual practices (pp. 83-96). Mahwah, New Jersey: Lawrence 
Erlbaum Associates, Publishers. DOI: $10.4324 / 9781410609526$

Bourdieu, P. (1986). The forms of Capital. In J. G. Richardson (Ed.), Handbook of theory and research for the sociology of education (pp. 241-258). Westpoint: Greenwood.

Bourdieu, P. (2000). The production and reproduction of legitimate language (1982). In L. Burke, et al. (Eds). The Routledge language and cultural theory reader (pp. 467-477). London: Routledge.

Cameron, D. (2001). Working with spoken discourse. London: SAGE. DOI: 10.4135/9781473921917

Canagarajah, S. (1993). Critical ethnography of a Sri Lankan classroom: Ambiguities in student opposition to reproduction through ESOL. TESOL Quarterly, 27(4), 60166. DOI: $10.2307 / 3587398$

Cope, B. \& Kalantzis, M. (1993). The power of literacy and the literacy of power. In B. Cope \& M. Kalantzis (Eds.), The power of literacy: A genre approach to teaching writing (pp. 63-89). London: The Falmer Press.

Corbett, J. (2003). An Intercultural approach to English language teaching. Clevedon: Multilingual Matters. DOI: $10.21832 / 9781853596858$

Corson, D. (1999). Language policy in schools: A resource book for teachers and administrators. Mahwah, New Jersey: Lawrence Erlbaum Associates, Publishers.

Cortazzi, M. \& Jin, L. (1999). Cultural mirrors: Materials and methods in the EFL classroom. In E. Hinkel (Ed.), Culture in second language teaching and learning. Cambridge: Cambridge University Press. DOI: 10.1016/S0346251X(00)00031-2

Crystal, D. (1997). English as a global language. Cambridge: Cambridge University Press. DOI: 10.1017/CBO9780511486999

Cummins, J. (2001a). Negotiating identities: Education for empowerment in a diverse society $\left(2^{\text {nd }}\right.$ ed). Los Angeles: California Association for Bilingual Education. 
Cummins, J. (2001b). Instructional conditions for trilingual development. International Journal of Bilingual Education and Bilingualism, 4(1), 61-75. DOI: 10.1080/13670050108667719

De Castell, S., Luke, A. \& Luke, C. (Eds.) (1989). Language authority and criticism: readings on the school textbook. London: The Falmer Press.

Delpit, L. (1988). The silenced dialogue: Power and pedagogy in educating other people's children. Harvard Educational Review, 58, 280-298. DOI: 10.17763/haer.58.3.

Delpit, L. (1995). Other people's children: Cultural conflict in the classroom. New York: The New Press.

Fairclough, N. (1989). Language and power. London: Longman. DOI: 017/S0047404500016316

Fairclough, N. (1992). Introduction. In N. Fairclough (ed.) Critical language awareness (pp. 1-29). London: Longman.

Fairclough, N. (1993). Critical discourse analysis and the marketization of public discourse: The universities. Discourse and Society, 4(2), 133-168. DOI: $10.1177 / 0957926593004002002$

Freire, P. (2000). Pedagogy of the oppressed. London: Bloomsbury Publishing.

Gray, J. (2002). The global coursebook in English language teaching. In D. Block \& D. Cameron (Eds.), Globalization and language teaching. (pp. 151-167) London: Routledge. DOI: $10.1002 / 9781444324068 . c h 12$

Gunesekera, M. (2005). The postcolonial identity of Sri Lankan English. Colombo: Katha.

Hall, S. (1994). Encoding/decoding. In D. Graddol \& O. BoydBarrett (Eds.), Media texts: Authors and readers (pp. 200211). Clevedon: Multilingual Matters.

Jenkins, J. (2003). World Englishes: A resource book for students. London: Routledge.

Klein, G. (1985). Reading into racism: Bias in children's literature and learning material. London Routledge. 
Kress, G. \& Van Leeuwen, T. (1996). Reading images: The grammar of visual design. London: Routledge.

McLaren, P. (1989). Life in schools: An introduction to critical pedagogy in the foundations of education. Toronto: Irvin Publishing.

Meyer, M. 1991. "Developing Transcultural Competence: Case Studies of Advanced Foreign Language Learners" in Buttjes, D. \& M. Byram (eds.), Mediating Languages and Cultures. Clevedon: Multilingual Matters Ltd.

Parakrama, A. (1995). De-hegemonizing language standards. London: Macmillan Press. DOI: 10.1057/9780230371309

Pennycook, A. (2001). Critical applied linguistics: A critical approach. Mahwah: Lawrence Earlbaum Associates, Publishers.

Sheldon, F. (1998). Evaluating ELT textbooks and materials. ELT Journal, 4(4), 237- 246.

Smitherman-Donaldson, G. \& Van Dijk, T. A. (1988). Introduction: Words that hurt. In G. Smithermaan-Donaldson \& T. A. van Dijk (Eds.) Discourse and discrimination. Detroit: Wayne State University Press.

Thompson, J. B. (1990). Ideology and modern culture. Cambridge: Polity Press.

Van Dijk, T. A. (1993a). Elite discourse and racism. Newbury Park: SAGE Publications. DOI:10.4135/9781483326184

Van Dijk, T. A. (1993b). Principles of critical discourse analysis. Discourse and Society, 4(2), 249-283. DOI: $10.1177 / 0957926593004002006$

Weiss, G. \& Wodak, R. (2003). Introduction: Theory, interdisciplinarity and critical discourse analysis. In G. Weiss \& R. Wodak (Eds.), Critical discourse analysis: Theory and interdisciplinarity. New York: Palgrave Macmillan. DOI: $10.1057 / 9780230288423$ 